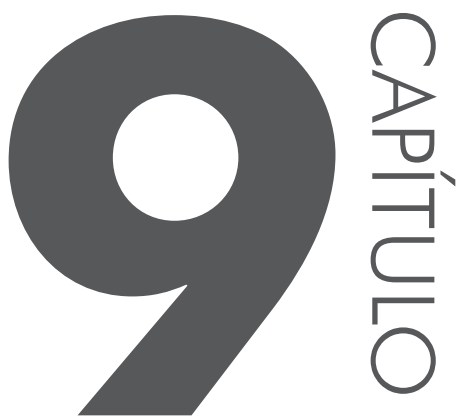

\title{
REDES SOCIAIS NO ENSINO SUPERIOR: UMA VISÃO DA TEORIA CONTINGENCIAL
}

\author{
André Luís Mázaro ${ }^{1}$ \\ Rosilda Pinto Ciríaco Mázaro ${ }^{1}$ \\ Daniely Rodovalho Macedo ${ }^{1}$ \\ Michelly de Melo Alves ${ }^{1}$ \\ Adriana Santos Prado Sadoyama, 2 \\ Geraldo Sadoyama ${ }^{1,3}$
}

1 Unidade Acadêmica Especial de Gestão e Negócios, Universidade Federal de Goiás - Regional Catalão, Catalão, Brasil.

2 Unidade Acadêmica Especial de Educação, Universidade Federal de Goiás - Regional Catalão, Catalão, Brasil.

3 Unidade Acadêmica Especial de Biotecnologia, Universidade Federal de Goiás - Regional Catalão, Catalão, Brasil.

E-mail de contato: andremazaro@hotmail.com, rosildaciriaco@hotmail.com, danyrmacedo@yahoo. com.br, michellymeloa@hotmail.com,drisadoyama@gmail.com,gsadoyama@yahoo.com.br 
Agradecimentos: Agradecemos a oportunidade de divulgação dos projetos de pesquisa do Mestrado Profissional em Gestão Organizacional da Universidade Federal de Goiás - Regional Catalão, bem como às pessoas envolvidas no III SPGPI.

Resumo: A intenção deste artigo foi o levantamento dos trabalhos desenvolvidos e da discussão teórica que tratam das redes sociais e suas influências no Ensino Superior no Brasil, pautando nessas argumentações como as redes sociais se relacionam dentro das instituições de Ensino Superior. A metodologia utilizada para elaboração deste trabalho foi uma pesquisa bibliográfica por meio de um mapeamento dos trabalhos publicados na Associação Nacional de Pós-Graduação e Pesquisa em Administração (ANPAD) e o Encontro de Estudos Organizacionais (EnEO) nas bases de artigos a partir de expressões-chave para o levantamento de todos os trabalhos desenvolvidos nos grupos de pesquisa no Brasil. Apesar da importância das redes sociais nas relações entre os indivíduos e suas organizações observou-se pouca utilização desta ferramenta em pesquisas educacionais no Brasil, concluindo que as influências das redes sociais na Educação Superior brasileira é um campo de pesquisa ainda em fase inicial.

Palavras-chave: Redes sociais. Redes de relacionamento. Ensino Superior.

Abstract: The intention of this article was a survey of the work performed and the theoretical discussion that deals with social networks and their influence on higher education in Brazil. Basing these arguments, how social networks are related within the higher education institutions. The methodology used for the preparation of this work was a literature search through a mapping of the published National Association of Graduate Studies and Research in Administration (ANPAD) and the Meeting of Organizational Studies (EnEO) in the article databases from the Key expressions for the lifting of all the work done in the research groups in Brazil. Despite the importance of social networks in the relations between individuals and their organizations there was little use of this tool in educational research in Brazil, concluding that the influence of social networks in Brazilian higher education is a field of research in the country still in the initial phase.

Keywords: Social networks. Social networks. Higher education.

\section{INTRODUC̣ÃO}

O objetivo principal deste artigo é analisar parte da discussão teórica que trata das redes sociais e suas influências no Ensino Superior brasileiro. A partir desta abordagem, é preciso contextualizar o termo redes sociais e suas origens. Dentro da visão das ciências sociais, segundo Karl Polanyi (1957), as relações sociais vêm do conceito de incrustação, do inglês embeddedneess. A nova sociologia econômica (NSE) retrata que a economia capitalista e os indivíduos estão inseridos nas redes de relações sociais. A abordagem para satisfação das necessi- 
dades humanas tem como objetivo o indivíduo que procura elevar ao máximo os seus ganhos. Polanyi $(1968,1977,2000)$ cita três formas de integração, sendo: reciprocidade, redistribuição e troca, este último com uma visão mercantilista (MACHADO, 2010).

Ao citar o indivíduo, resgatam-se as relações sociais, a cultura e o meio ambiente em que se está inserido. Segundo Lima (2013), a visão de cultura seria o conhecimento que inclui crenças, arte, moral, leis, costumes e todos os outros hábitos e aptidões adquiridos pelo homem enquanto membro de uma sociedade (LARAIA, 2001 apud LIMA 2013). A Teoria da Contingência Estrutural estabelece que a estrutura organizacional das organizações não é única, sendo influenciada por vários fatores, como estratégias da organização, tamanho, inovação e ambiente em que estão incluídas: o indivíduo inserido no meio com suas necessidades psicológicas e sociais (DONALDSON, 1996 apud CLEGG et al., 2007).

As práticas sociais regidas pela cultura direciona o comportamento dos indivíduos, definindo o comportamento das pessoas, frente aos ambientes pautados nas crenças e valores (VASCONCELOS-SILVA; BUENO, 2013). Segundo Hofstede (1991) os indivíduos se comportam em conformidade com padrões grupais (Lima, 2013).

A partir desta visão, percebemos e sistematizamos as tendências do tema abordado e o que levam à discussão sobre o assunto pelos pesquisadores sobre as redes sociais e a organização.

Ao fazermos o levantamento de todos os estudos feitos nas bases de dados dos trabalhos publicados na Associação Nacional de Pós-Graduação e Pesquisa em Administração (ANPAD), Encontro de Estudos Organizacionais (EnEO) que envolveram redes sociais, percebemos que as discussões a respeito do tema na Educação Superior estão em fase inicial e seguiram a linha das redes de relacionamento. A revisão da literatura nos permitiu produzir alguns enfoques principais: a perspectiva conceitual sobre redes sociais e o envolvimento dos indivíduos com a organização e o relacionamento com as instituições de Ensino Superior.

Ao refletirmos sobre o sentido das redes sociais na Educação Superior equacionamos a ideia de que quando começamos um conceito de valores na educação, há que se ponderar sobre o processo para medi-la, bem como o destino a dar e as motivações que a justificam. Posto isto, falar de redes sociais no Ensino Superior implica sabermos o que se entende por redes sociais e como os indivíduos se relacionam em grupos. Nos vários estudos realizados, chama-se a atenção para o comportamento das pessoas em grupo e a práticas sociais.

\subsection{Redes sociais}

Em termos intuitivos, redes sociais são conjuntos de contatos que ligam vários atores (NELSON, 1984). Estes atores podem estar presentes no mesmo espa- 
ço físico de uma organização acadêmica, em uma mesma cidade ou em localidades diferentes, porém constituírem suas redes através de encontros, elaborando convênios, intercâmbio de professores e alunos e demais métodos que possam colaborar com a troca e produção de conhecimento.

Para os teóricos de redes, seria a matéria principal da vida social: as redes concretas de relações sociais que, ao mesmo tempo, incorporam e transcendem organizações e instituições convencionais (MIZRUCHI, 2006). Este é o ponto para se encontrar nos artigos: essa transcendência das redes nas organizações para estabelecimento de relações sociais.

A presença de relações sociais com objetivos organizacionais, ou seja, intenções de melhorar uma organização com aquisição de conhecimento através do compartilhamento de métodos de ensino e pesquisa ou parcerias entre seus docentes e os docentes de outras Instituições de Ensino Superior (IES), mostra a mudança das relações de poder entre elas, pois, para atingirem um objetivo comum, estas se unem em prol da ampliação dos seus conhecimentos, utilizando a premissa de que o conhecimento é poder. Um exemplo histórico claro dessa interação entre IES é a necessidade brasileira de professores em administração serem treinados no exterior para o estabelecimento e o fortalecimento do currículo dos cursos no país. A maioria dos docentes em administração é treinada no exterior e obteve graus acadêmicos em universidades americanas (BERTERO; KEINERT, 1994).

As estruturas de redes podem ser classificadas como densas ou escassas; estáveis ou não; centralizadas ou descentralizadas; ligadas ou desligadas. Ligações entre atores podem ser classificadas em relação a atributos individuais, como necessidade ou simetria conforme Nelson (1984). As redes sociais podem ser analisadas e classificadas de diversas formas. Além do seu conteúdo, as redes podem ser identificadas de acordo com suas propriedades estruturais ou com a natureza dos contatos individuais.

O conceito e a ideia de que a diversidade de relações sociais traz ganhos foi desenvolvida desde o terceiro quartil do século passado. Granovetter (1985) reflete que as alianças entre indivíduos poderiam trazer vantagens para compartilhamento de recursos. Para compreender as redes interorganizações é fundamental que se possa entendê-las de forma sistemática com a conceituação de "nós e elos". "Nós" são definidos como pontos da rede, enquanto "elos" são as ligações que existem entre os nós, por exemplo, nós sendo os indivíduos ou grupos e elos as relações que existem entre eles (GRANOVETTER, 1985 apud CUNHA et al., 2010).

Ainda segundo os autores Cunha et al. (2010), as ligações entre os nós podem variar em duas dimensões: a primeira em que relações que podem ser estabelecidas com organizações do mesmo setor, e a segunda em que as ligações podem ser mais resistentes do que outras. Essas ligações podem ser definidas como dois 
tipos: as ligações fortes, que são feitas por maior proximidade e as ligações fracas, que não apresentam tanta proximidade.

Essas análises de como são os relacionamentos dos atores dentro das redes sociais é que nos trazem o interesse da pesquisa: quais circunstâncias levam pessoas com diferentes objetivos, até então, a se unirem em prol de uma relação que favoreça a ambos? Existe também a necessidade de compreender a estrutura das organizações das IES, assim Nelson (1984) diz que “(...) a estrutura organizacional [é] definida como redes múltiplas de comportamentos interligados”. Dito isso, vê-se a necessidade de fundamentar a estrutura organizacional das IES no Brasil conforme o cenário descrito nos textos encontrados.

\subsection{Teoria da Contingência Estrutural}

As IES se configuram como organizações, sejam elas de origem econômica privada ou pública. Partindo deste princípio, podemos verificar a aplicação da Teoria da Contingência Estrutural, pois ela tem fornecido um paradigma coerente para a análise da estrutura das organizações (DONALDSON, 2007) que, no artigo, se aplica favoravelmente a relações sociais dentro do ambiente organizacional. O conjunto recorrente de relacionamentos entre os membros da organização pode ser considerado como sendo a estrutura da organização (DONALDSON, 2007). Estes relacionamentos não se restringem apenas aos atores sociais que estão dentro da organização, mas também às suas hierarquias, que estão acontecendo durante todo o tempo.

Dentro do contexto dos relacionamentos, Silva e Cunha (2012) explica que as transições humanas são experiências carregadas de emoções, desafios, perdas e oportunidades. Muitas das vezes essas características são ignoradas ou minimizadas por gerentes e outros membros dentro de uma organização; a realidade é que elas afetam o desempenho e funcionamento das organizações e as relações entre os indivíduos e equipe.

Mesmo essas relações dentro das organizações sendo mistas entre os diversos níveis de poder existentes na hierarquia, existe a necessidade de implantar estruturas em formato de regras, que vão organizar a estrutura da organização. Este modelo estrutural deve ser originário de cada organização, não sendo oportuno importar modelos de outras organizações.

Estudos relativos à criação de processos de conhecimento e aprendizagem dentro das organizações é sempre uma necessidade, pois tais trabalhos procuram entender o modo de como esses processos podem ser influenciados, bem como compreender a relação de aprendizagem individual e aprendizagem organizacional, os papéis dos líderes e as relações entre a equipe influenciam os processos. As universidades têm estabelecido estudos em grupos de pesquisas que têm sido considerados 
bastante viáveis para compreender os motivos pelos quais os pesquisadores colaboram entre si e o papel dessa colaboração na qualidade e na quantidade de publicações, bem como na formação de grupos sociais (ODELIUS et al., 2010).

Há diversos fatores contingenciais: estratégia, tamanho, incerteza com relação às tarefas e tecnologia. Essas características organizacionais, por sua vez refletem a influência do ambiente em que a organização está inserida (DONALDSON, 2007). Reforçando que mudanças de cenário referente às organizações de Ensino Superior existentes no país impulsionaram o surgimento das relações sociais.

Contrapõe-se a isso o estudo da sociologia estrutural, que traz uma abordagem sobre estruturas sociais, restrições e oportunidades que são vistas como afetando mais o comportamento humano do que as normas culturais ou outras condições subjetivas (MIZRUCHI, 2006), o que revela a necessidade de entendimento do posicionamento da IES na rede de relações sociais entre as demais que façam parte do mesmo cenário.

\subsection{Organizações de Ensino Superior}

No contexto brasileiro, as IES públicas ou privadas garantem a prestação dos serviços educacionais com qualidade, em busca do crescimento social, político e econômico da comunidade em que estão inseridas (MÁZARO et al., 2014).

A questão das IES mostra uma dicotomia de objetivos, sendo estas responsáveis pela formação de cidadão através do ensino e, em algumas instituições, com foco na pesquisa. Por meio de um olhar para a sociedade em geral, identifica-se a necessidade da melhoria das condições de vida da população, e como os melhores posicionamentos sociais surgem a partir do momento em que o indivíduo tem qualificação para o trabalho, a carreira de docente no Ensino Superior tem ganhado visibilidade no mercado de trabalho. Porém, há a necessidade destes docentes serem qualificados para incentivarem a pesquisa em suas instituições com a contribuição dos alunos, conforme Rowe, Bastos e Pinho (2010). Essa categoria tem vivenciado um crescimento vertiginoso nos últimos anos pela expansão do Ensino Superior no Brasil, que tem uma das maiores redes de educação superior em termos mundiais: a maior da América do Sul e a sétima do mundo, enquanto os Estados Unidos são a vigésima (ROWE; BASTOS; PINHO, 2010).

O governo federal tem criado programas de incentivo para as universidades, com o Programa de Apoio a Planos de Reestruturação e Expansão das Universidades Federais (Reuni) instituído pelo Decreto n ${ }^{\circ}$ 6.096, de 24 de abril de 2007, complementado as ações do Plano de Desenvolvimento da Educação, incentivando o Ensino Superior, bem como também facilitando o acesso da população aos cursos superiores por meio de programas de bolsas (Programa Universidade para Todos - ProUni - e Sistema de Seleção Unificada - Sisu), financiamento estudan- 
til (Fies), sistema de cotas e convênios com IES fora do país para estudantes de graduação e pós-graduação, no intuito de melhorar a qualidade do ensino com avaliações institucionais (Enade) e pesquisa no país.

É neste momento que se observa um movimento de fortalecimento das redes sociais entre as IES, vendo a necessidade por meio dos incentivos governamentais de terem produções científicas de qualidade, inovadoras e que acrescentem à sociedade em que estão inseridas, operando mudanças na realidade local. O campo da pesquisa em Administração no Brasil apresentou forte crescimento nos últimos anos (ROSSONI; GUARIDO FILHO, 2009).

Evidências do aumento da cooperação entre pesquisadores e programas de pós-graduação no âmbito da produção científica têm favorecido a compreensão da construção do conhecimento científico não como empreendimento individual, mas imerso em redes de relacionamentos (ROSSONI; GUARIDO FILHO, 2009).

De acordo com Heinzmann, Machado e Ropelato (2010), que trazem, em sua pesquisa realizada no período de 1998 a 2009 na Anpad, “com base nesses resultados, infere-se que a produção científica nacional na área de cultura organizacional é produzida por grupos de pesquisa formada por pesquisadores de diferentes instituições". Viu-se que, apesar das redes entre os autores serem fracas, as existentes entre as instituições são mais fortes. Isto permite que instituições de diferentes regiões do Brasil tenham acesso à produção de artigos científicos que explorem essa temática e contribuam para eles.

Com isso, as instituições reforçam suas redes de relacionamento e não há necessidade de que sejam do mesmo segmento, podendo ocorrer parcerias público-privadas ou mesmo com instituições internacionais, com um grupo com vários pesquisadores de diferentes instituições, mas que estejam envolvidos em um mesmo projeto de pesquisa, que no final engrandecerá ambas as IES envolvidas. Segundo Honório e Sá (2010), durante a análise de dados, pôde-se ver como essas interações sociais no ambiente de trabalho influem na aprendizagem de conhecimento, ideias, pensamentos e interpretações, o que traz benefícios não somente para os profissionais, mas também para as pessoas e, principalmente, para as organizações, visto que a aprendizagem se torna imprescindível para que elas possam atingir, manter e aumentar a sua efetividade e competitividade em seu campo de atuação.

Desta maneira, evidencia-se o crescimento das instituições enquanto produtoras de conhecimento, enquanto ocorre a melhora na qualidade da oferta do ensino e pesquisa para seus alunos, garantindo a visibilidade de mercado na divulgação destes convênios com outras IES de tradição ou mesmo instituições de ensino internacionais, fortalecendo a rede social e ampliando-a com a participação, em diferentes níveis de atuação e contribuição para essa rede, dos acadêmicos participantes de programas entre IES. 


\section{MÉTODO}

Para a elaboração desse trabalho, foi utilizado o método proposto por Montero e Leon (2007) para o mapeamento de pesquisas. Este mapeamento considera a busca de estudos cadastrados em bases de dados que contém quantidade de publicações e que possibilitam o uso de expressões lógicas para a seleção dos artigos. No presente trabalho, utilizamos o método para a seleção dos artigos a partir de expressões-chave.

Segundo Araújo (2006), a bibliometria é a utilização de métodos e técnicas que envolvem a quantificação e a estatística de medição dos índices de produção e disseminação do conhecimento científico. Neste artigo, busca-se aplicar a lei clássica de Zipf, uma técnica bibliométrica que busca quantificar o número de vezes e a frequência do uso das palavras nos textos pesquisados. A quantidade de vezes que estas palavras aparecem no texto indica o assunto do documento, sendo que o foco da pesquisa é redes sociais.

Assim, a base de dados consideradas nesse estudo foi a Associação Nacional de Pós-Graduação e Pesquisa em Administração (ANPAD) dentro dos Encontros de Estudos Organizacionais (EnEO), destacando que foram analisados somente artigos. As expressões lógicas empregadas foram: "redes sociais", "redes de relacionamento", "Ensino Superior" e "redes sociais no Ensino Superior".

Após a coleta, com foco nos artigos da EnEO, foi efetuada uma análise dos títulos, palavras-chave e resumos, de modo a extrair os assuntos discutidos e se os trabalhos publicados se relacionavam diretamente ao tema em estudo, sendo a revisão da bibliografia desenvolvida a partir do número final de estudos obtidos. Após a leitura dos pontos elencados, a coleta foi transferida para uma planilha Microsoft Excel que envolveu os seguintes dados: (a) título do artigo; (b) nome dos autores; (c) número do periódico; (d) enfoque - redes sociais, redes de relacionamento e Ensino Superior. Extraíram-se os assuntos levantados de cada artigo, sendo que alguns tiveram sua leitura aprofundada para a introdução e referencial teórico para identificação. Os dados pesquisados foram transcritos para as tabelas que serão apresentadas nos resultados.

A pesquisa limitou-se aos anos de 2010 a 2012 na busca dos artigos que tinham como título a expressão redes sociais, de modo especial no Ensino Superior, em que os critérios utilizados eram as redes sociais aplicadas a educação, valores culturais, reciprocidade, redistribuição e troca mercantil, com foco nos grupos sociais de Ensino Superior.

\section{RESULTADOS}

Os resultados do mapeamento foram obtidos a partir da leitura dos resumos dos artigos selecionados, que totalizaram 35 trabalhos. A Tabela 1 apresenta um tópico principal para o agrupamento dos resultados obtidos: redes sociais. 
Tabela 1. Redes sociais

\begin{tabular}{|c|c|c|}
\hline \multirow{2}{*}{$\begin{array}{c}\text { ANPAD - EnEO } \\
\text { Assunto }\end{array}$} & \multicolumn{2}{|c|}{ ANOS } \\
\hline & 2010 & 2012 \\
\hline Dimensão cultural de uma organização (IES) & 1 & \\
\hline Empreendedorismo feminino IES & 1 & \\
\hline Cultura organizacional nas IES & 1 & \\
\hline Relação de comunicação e tomada de decisão & 1 & \\
\hline Redes de negócios & 1 & \\
\hline Redes de supermercado & 1 & \\
\hline Construção de identidades de culturais de destinos turísticos & 1 & \\
\hline Stakeholders no setor eletroeletrônico & 1 & \\
\hline Categorização das redes & 1 & \\
\hline $\begin{array}{l}\text { Rede horizontal, compartilhamento de informação e conheci- } \\
\text { mento }\end{array}$ & 1 & \\
\hline Comunicação organizacional de gestão de obras & 1 & \\
\hline Gestão social & 1 & \\
\hline Politicas públicas culturais & 1 & \\
\hline Participação política e o uso político da TIC & 1 & \\
\hline Processo de aprendizagem em grupos de trabalho & 1 & \\
\hline Serviços financeiros, cooperativa crédito rural & & 1 \\
\hline Narrativas de aprendizagem & & 1 \\
\hline Formas organizacionais & & 1 \\
\hline Gestão do Conselho Alimentar & & 1 \\
\hline Relacionamento com o mercado Wall Stret & & 1 \\
\hline Aposentadoria de executivos & & 1 \\
\hline Crimes corporativos & & 1 \\
\hline Associação dos produtores de vinho & & 1 \\
\hline Governança em redes & & 1 \\
\hline Rede organização não governamental & & 1 \\
\hline Total & 15 & 10 \\
\hline
\end{tabular}

Fonte: ANPAD, 2015.

Na Tabela 1, para o ano de 2010, evidenciam-se os assuntos que possuem elo com as redes sociais: Dimensão cultural de uma organização (IES); Empreendedorismo feminino IES; Cultura organizacional nas IES; Relação de comunicação e tomada de decisão; Redes de negócios; Redes de supermercado; Construção de identidades culturais de destinos turísticos; Stakeholders no setor eletroeletrôni- 
co; Categorização das redes; Rede horizontal, compartilhamento de informação e conhecimento; Comunicação organizacional de gestão de obras; Gestão social; Politicas públicas culturais; Participação política e o uso político da TIC; e Processo de aprendizagem em grupos de trabalho. Cada um destes assuntos possui um artigo, totalizando assim 15 trabalhos.

Para as pesquisas do ano 2012 os seguintes assuntos foram escolhidos: Serviços financeiros, Cooperativa crédito rural; Narrativas de aprendizagem; Formas organizacionais; Gestão do Conselho Alimentar; Relacionamento com o mercado Wall Street; Aposentadoria de executivos; Crimes corporativos; Associação dos produtores de vinho; Governança em redes; Rede organização não governamental, com 1 artigo para cada assunto, totalizando 10. A Tabela 2 apresenta o mapeamento, com o resultado de 10 artigos que apresentam os resultados obtidos para redes de relacionamento.

Tabela 2. Redes de relacionamento

\begin{tabular}{ccc}
\hline ANPAD - EnEO & \multicolumn{2}{c}{ ANOS } \\
\hline Assunto & 2010 & $\mathbf{2 0 1 2}$ \\
\hline Empresa familiar & 1 & 1 \\
Identidade organizacional nos processos de fusões e & 1 & \\
aquisições de empresas & 1 & \\
Operação de redes imobiliárias & 1 & \\
História intelectual nos estudos organizacionais & 1 & 1 \\
Relações humanas na gestão do setor hoteleiro & 1 & 1 \\
Gênero masculino na empresa petroquímica & & 1 \\
Benefícios de redes & & 4 \\
Empresa multinacional brasileira & & \\
Carreira de bancário & 6 & \\
Total & &
\end{tabular}

Fonte: ANPAD, 2015.

Em relação aos resultados obtidos sobre redes de relacionamento na Tabela 2, foram selecionados 10 artigos no total, sendo que em 2010 foram 6, com os seguintes assuntos: Empresa familiar; Identidade organizacional nos processos de fusões e aquisições de empresas; Operação de redes imobiliárias; História intelectual nos estudos organizacionais; Relações humanas na gestão do setor hoteleiro; e Gênero masculino na empresa petroquímica, com 1 artigo para cada uma destas palavras-chave. Em 2012, foram selecionados 4 artigos, sendo que os assuntos encontrados foram: Empresa familiar; Benefícios de redes; Empresa multinacional brasileira; e Carreira de bancário. Pode-se observar a repetição do assunto 
Empresa familiar. A Tabela 3 apresenta os resultados obtidos em 28 artigos: Ensino Superior.

Tabela 3. Ensino Superior

\begin{tabular}{|c|c|c|}
\hline \multirow{2}{*}{$\begin{array}{c}\text { ANPAD - EnEO } \\
\text { Assunto } \\
\end{array}$} & \multicolumn{2}{|c|}{ ANOS } \\
\hline & 2010 & 2012 \\
\hline Relacionamento com stakeholders & 1 & \\
\hline Comprometimento organizacional & 2 & \\
\hline Processo de gestão focado em planejamento e orçamento & 1 & \\
\hline Ato de consumir, consumir consciente & 1 & \\
\hline Redes de pesquisa & 1 & \\
\hline Vivência cotidiana & 1 & \\
\hline Perfil da mulher nas cooperativas de Monte Carmelo-MG & 1 & \\
\hline Comunicação para o uso da energia elétrica & 1 & \\
\hline Relações em uma organização familiar & 1 & \\
\hline Feminismos nos estudos organizacionais & 1 & \\
\hline Gestão de pessoas & 1 & \\
\hline Aprendizagem organizacional & 1 & \\
\hline $\begin{array}{l}\text { Processos de institucionalização e formação } \\
\text { de administradores }\end{array}$ & 1 & \\
\hline Narrativas de aprendizagem & & 1 \\
\hline Processo de afastamento no trabalho & & 1 \\
\hline Meditações funcionalistas & & 1 \\
\hline Líder universitário: relações interpessoais & & 1 \\
\hline Processo de formação de gestores & & 1 \\
\hline Cultura organizacional e poder em Foucault & & 1 \\
\hline $\begin{array}{l}\text { Aprendizagem tradicional e aprendizagem situada } \\
\text { em organizações }\end{array}$ & & 1 \\
\hline Envelhecimento populacional & & 2 \\
\hline Comprometimento organizacional em empresa júnior & & 1 \\
\hline Contradições na política científica e tecnológica & & 1 \\
\hline Carreira de bancário & & 1 \\
\hline Reivindicações sociais pela luta de classe & & 1 \\
\hline Sentidos e significados do trabalho & & 1 \\
\hline Total & 14 & 14 \\
\hline
\end{tabular}


Com a palavra-chave "Ensino Superior", os resultados em 2010 foram: Relacionamento com stakeholders; Processo de gestão focado em planejamento e orçamento; Ato de consumir, consumir consciente; Redes de pesquisa; Vivência cotidiana; Perfil da mulher nas cooperativas de Monte Carmelo-MG; Comunicação para o uso da energia elétrica; Relações em uma organização familiar; Feminismos nos estudos organizacionais; Gestão de pessoas; Aprendizagem organizacional; e Processos de institucionalização e formação de administradores com 1 artigo, e Comprometimento organizacional com 2 artigos, totalizando assim 14 trabalhos. No ano de 2012, os assuntos selecionados foram: Narrativas de aprendizagem; Processo de afastamento no trabalho; Meditações funcionalistas; Líder universitário: relações interpessoais; Processo de formação de gestores; Cultura organizacional e poder em Foucault; Aprendizagem tradicional e aprendizagem situada em organizações; Comprometimento organizacional em empresa júnior; Contradições na política científica e tecnológica; Carreira de bancário; Reivindicações sociais pela luta de classe; e Sentidos e significados do trabalho com 1 artigo cada, e Envelhecimento populacional com 2 artigos encontrados, totalizando 14 artigos.

Os artigos que não apresentaram elos com as redes sociais no Ensino Superior foram excluídos do mapeamento, sendo os assuntos no ano de 2010 para o termo "redes sociais": Comunicação organizacional de gestão de obras; Gestão social; Políticas públicas culturais; Participação política e o uso político da TIC; e Processo de aprendizagem em grupos de trabalho, totalizando 5 trabalhos. Para a expressão "redes de relacionamento" no ano de 2010, foram excluídos os artigos com os assuntos: Empresa familiar; História intelectual nos estudos organizacionais; Relações humanas na gestão do setor hoteleiro; e Gênero masculino na empresa petroquímica. No ano de 2012, o assunto Empresa familiar se repete, seguido de Carreira de bancário, totalizando 2 artigos excluídos.

Com a expressão "Ensino Superior", os artigos de exclusão foram os que abordavam os assuntos: Processo de afastamento no trabalho; Meditações funcionalistas; Cultura organizacional e poder em Foucault; Aprendizagem tradicional e aprendizagem situada em organizações; Envelhecimento dos assistentes sociais; Carreira de bancário; e Sentidos e significados do trabalho, totalizando 7 artigos

Entre os artigos que abordam redes sociais com enfoque no Ensino Superior, observou-se que poucos trataram das especificidades das relações sociais das universidades, centros e faculdades. Pode-se ressaltar que falar de redes sociais na educação é complexo, pois vai além de só avaliar os grupos sociais, incluindo também mensurar os processos sociais e individuais de uma IES.

As redes sociais de instituições de Ensino Superior podem ser mensuradas pela taxa de sucesso organizacional? Essa pergunta deve ser respondida a partir dos dados deste trabalho de revisão. Ao levantarmos estas informações, elenca- 
mos questões bem específicas sobre o provável conceito de redes sociais no Ensino Superior. O resultado encontrado segue um parâmetro bastante específico.

Podemos perceber, na leitura dos títulos juntamente com os resumos, a seguinte situação: na base de dados da ANPAD/EnEO, dos 61 trabalhos analisados, 4 artigos foram publicados por 1 autor; 27 artigos por 2 autores; 17 artigos por 3 autores; 8 artigos por 4 autores; 3 artigos por 5 autores e 2 artigos por 6 autores. Somente 3 artigos tratavam diretamente das redes sociais no Ensino Superior. Ao citar a quantidade de publicações por autores, percebe-se que, quando o número de autores por publicação é maior, acontecem as redes sociais, bem como o relacionamento entre as IES. Porém, pode-se dizer que o assunto é pouco explorado na literatura brasileira.

\section{CONCLUSÃO}

Avaliando e analisando todos os trabalhos sobre redes sociais na Educação Superior, percebemos a necessidade epistemológica de estudos voltados para esta organização educacional sob a ótica de uma política de funcionamento do processo educativo do ensino aliado à gestão da organização deste. Afirmamos que esta revisão de literatura nos permitiu verificar a necessidade de avaliar, mensurar e disseminar no âmbito educacional as redes sociais no Ensino Superior.

Este trabalho se propôs a analisar teoricamente a redes sociais e suas influências no Ensino Superior em todos os seus aspectos culturais e valores dos grupos sociais, bem como os seus relacionamentos. Durante os estudos, pôde-se perceber uma preocupação com as redes sociais em detrimento das especificidades dos processos educativos nas pesquisas mapeadas.

Quanto à sua relevância aos estudos organizacionais, conforme dito por Rese et al. (2010): “(...) as organizações bem como a estratégia (o fenômeno organizacional em estudo) são vistas também como socialmente construídas, legítimas e institucionalizadas a partir das interações e práticas sociais" entre os grupos de IES e seu corpo docente e alunos, aos quais se aplicou o estudo.

A metodologia utilizada foi a de mapeamento de pesquisas proposta por Montero e Leon (2007), o que nos permitiu compreender como a organização educacional se posiciona em relação a redes sociais, redes de relacionamento e Ensino Superior. O recorte da pesquisa esteve na busca dos artigos que apresentassem em seus títulos a palavra redes sociais para que posteriormente fossem analisados os resumos e o estreitamento com os grupos sociais. As expressões empregadas para alcançar o objetivo da pesquisa foram "redes sociais"; "redes de relacionamento"; e "redes sociais no Ensino Superior", selecionando, desta forma, trabalhos que estivessem diretamente voltados ao mapeamento. Este mapeamento nos oportunizou refletir sobre a importância de desenvolvimento 
de pesquisas voltadas a outras questões pertinentes às instituições educacionais. Dentre eles, podemos destacar o artigo desenvolvido por Heinzmann, Machado e Ropelato (2010) que traz um recorte do relacionamento das Instituições Superiores, porém limitado ao aspecto cultural.

A crítica é estabelecida quando os elos de relacionamento acontecem prioritariamente com as instituições e não com os indivíduos, como citado por Heinzmann, Machado e Ropelato (2010). Ela é ratificada com os dados quantitativos, quando o relacionamento entre as publicações levantadas por número de autores, em que conseguimos identificar somente dois autores que tiveram parcerias em outras publicações, sendo Cristina Amélia Carvalho nos anos de 2010 e 2012 e Patrícia Augusta Pospichil Chaves Locatelli no ano de 2012, ambas com duas publicações. Portanto, deve ser considerada a ampliação do estudo sobre redes sociais no Ensino Superior nas futuras pesquisas como forma de asseverar a credibilidade na análise dos indicadores da qualidade relacionados ao Ensino Superior, que tanto contribuem com o desenvolvimento das IES e dos indivíduos relacionados ao ambiente competitivo atualmente.

\section{REFERÊNCIAS}

ARAÚJO, C. A. Bibliometria: evolução histórica e questões atuais. Revista Em Questão, Porto Alegre, v. 12, n. 1, p. 11-32, jan/jun. 2006.

BERTERO, C. O.; KEINERT, T. M. M. A evolução da análise organizacional no Brasil (1961-93). Revista de Administração de Empresas, São Paulo, v. 34, n. 3, p. 81-90, maio/jun. 1994.

CUNHA, J. A. C.; PASSADOR, J. L.; PASSADOR, C. S. Categorizações e recomendações para a pesquisa sobre redes inter-organizacionais. In: VI Encontro de Estudos Organizacionais da ANPAD, 2010, Florianópolis. Anais eletrônicos... Florianópolis: EnEO, 2010.

DONALDSON, L. Teoria da Contingência Estrutural. In: CLEGG, S.; HARDY, C.; NORDY, W.; CALDAS, M.; FACHIN, R.; FISCHER, T. (Org.) Handbook de estudos organizacionais. São Paulo: Atlas, 2007.

HEINZMANN, L. M.; MACHADO, D. D. P. N.; ROPELATO, M. Cultura organizacional: redes formadas na literatura nacional. In: VI Encontro de Estudos Organizacionais da ANPAD, 6, 2010, Florianópolis. Anais eletrônicos... Florianópolis: EnEO, 2010.

HOFSTEDE, G. Cultures and organizations: software of the mind. Nova York: McGraw-Hill, 1991.

HONÓRIO, J. B.; SÁ, M. A. D. Aprendizagem organizacional: É relacionando-se que se aprende! In: VI Encontro de Estudos Organizacionais da ANPAD, 2010, Florianópolis. Anais eletrônicos... Florianópolis: EnEO, 2010. 
LIMA, D. M. C. A cultura organizacional do Tribunal de Justiça do Estado da Bahia: uma abordagem baseada nas contribuições de autores do pensamento social brasileiro. Tese (Doutorado em Administração) - Escola Brasileira de Administração Pública e de Empresas da Fundação Getúlio Vargas, Rio de Janeiro, 2013. 164 p.

MACHADO, N. M. C. Karl Polanyi e a nova sociologia económica: Notas sobre o conceito de (dis)embeddedness, Revista Crítica de Ciências Sociais, v. 90, 2010.

MASCARENHAS, A. O. Etnografia e cultura organizacional: uma contribuição da antropologia à administração de empresas. Revista de Administração de Empresas, São Paulo, v. 42, n. 2, p.88-94, 2002. Acesso em: 21 abr. 2015.

MÁZARO, A. L.; LEAL, G. S.; ROSALEM, V.; SADOYAMA, A. S. P. Percepção da qualidade de serviços educacionais em instituição de ensino superior privada em Catalão, GO. Enciclopédia Biosfera, Goiânia, v. 10, n. 19, 2014.

MIZRUCHI, M. S. Análise de redes sociais: avanços recentes e controvérsias atuais. Revista de Administração de Empresas, São Paulo, v. 46, n. 3, jul./set. 2006.

MONTERO, I.; LEÓN, O. G. A guide for naming research studies in Psychology. International Journal of Clinical and Health Psychology, v. 7, n. 3, p. 847-862, 2007.

NELSON, R. O uso da análise de redes sociais no estudo das estruturas organizacionais. Revista de Administração de Empresas, São Paulo, v. 24, n. 4, p. 150-157, out/dez. 1984. ODELIUS, C. C.; ABBAD, G. S.; RESENDE JUNIOR, P. C.; SENA, A. C.; SANTOS, T. C. N.; FREITAS, T. L. Processos de aprendizagem, competências aprendidas, funcionamento, compartilhamento e armazenagem de conhecimentos em grupos de pesquisa. In: VI Encontro de Estudos Organizacionais da ANPAD, 2010, Florianópolis. Anais eletrônicos... Florianópolis: EnEO, 2010.

RESE, N.; MONTENEGRO, L. M.; BULGACOV, S.; BULGACOV, Y. L. M. A análise de narrativas como metodologia possível para os estudos organizacionais sob a perspectiva da estratégia como prática: "Uma estória baseada em fatos reais". In: VI Encontro de Estudos Organizacionais da ANPAD, 2010, Florianópolis. Anais eletrônicos... Florianópolis: EnEO, 2010.

ROSSONI, L.; GUARIDO FILHO, E. R. Cooperação entre programas de pósgraduação em Administração no Brasil: evidências estruturais em quatro áreas temáticas. Revista de Administração Contemporânea, v. 13, n. 3, p. 366-390, 2009. ROWE, D. E. O.; BASTOS, A. V. B.; PINHO, A. P. M. O comprometimento organizacional e o esforço institucional de docentes do ensino superior: explorando o impacto das diferentes bases do comprometimento. In: VI Encontro de Estudos Organizacionais da ANPAD, 2010, Florianópolis. Anais eletrônicos... Florianópolis: EnEO, 2010.

SILVA, F. M. V.; CUNHA, C. J. C. A. Tornar-se líder universitário: o significado das relações interpessoais. In: VII Encontro de Estudos Organizacionais da ANPAD, 2012, Curitiba. Anais eletrônicos... Curitiba: EnEO, 2012.

VASCONCELOS-SILVA, A.; BUENO, M. (Org.) Concepções contemporâneas sobre organização e trabalho. Goiânia: DEPECAC-UFG/FUNAPE, 2013. 
